\title{
Glomerular Hypertrophy Aggravates Epithelial Cell Injury in Nephrotic Rats
}

Peter L. Miller, James W. Scholey, Helmut G. Rennke, and Timothy W. Meyer

Department of Medicine, Stanford University, Stanford, California 94305; Department of Medicine, Palo Alto Veterans Administration

Medical Center, Palo Alto, California 94304; and Department of Pathology, Brigham and Women's Hospital and

Harvard Medical School, Boston, Massachusetts 02115

\begin{abstract}
Glomerular function and structure were assessed after reduction of nephron number and restriction of protein intake in rats with adriamycin nephrosis. Rats received an injection of adriamycin and were divided into three groups with similar values for albuminuria after 4 wk. Group 1 rats then served as controls, group 2 rats were subjected to four-fifths renal ablation, and group 3 rats were placed on a low protein diet (8\% protein) while group 1 and group 2 rats remained on a standard diet ( $24 \%$ protein). Micropuncture and morphometric studies were performed 10 d later. Estimated single-nephron albuminuria $\left(\mathrm{SN}_{\mathrm{alb}}\right)$ was increased by renal ablation in group 2 and decreased by protein restriction in group 3 (group 1, 20 $\pm 2 \mu \mathrm{g} / \mathrm{d}$; group 2, 68 $\pm 7 \mu \mathrm{g} / \mathrm{d}$; group 3, $12 \pm 1 \mu \mathrm{g} / \mathrm{d}, P<0.05$ groups 2 and 3 vs. 1). Increased $\mathrm{SN}_{\text {alb }}$ was associated with increased glomerular volume in group 2 and reduced $\mathrm{SN}_{\text {alb }}$ was associated with reduced glomerular volume in group 3. (group 1, $1.44 \pm 0.04 \times 10^{6}{\mu \mathrm{m}^{3}}^{3}$ group $2,1.66 \pm 0.08 \times 10^{6} \mu \mathrm{m}^{3}$; group 3 , $1.26 \pm 0.03 \times 10^{6} \mu \mathrm{m}^{3}, P<0.05$ groups 2 and 3 vs. 1). Increased $\mathrm{SN}_{\text {alb }}$ in group 2 was not associated with an increase in glomerular transcapillary hydraulic pressure. The area of epithelial cell detachment from the peripheral capillary wall was markedly increased in group 2 but not perceptibly altered in group 3 (group 1, 16 $\pm 5 \times 10^{2} \mu \mathrm{m}^{2} ;$ group $2,65 \pm 17 \times 10^{2} \mu \mathrm{m}^{2}$; group 3, 18 $\pm 5 \times 10^{2} \mu^{2} ; P<0.05$ group 2 vs. 1). These studies show that glomerular hypertrophy is associated with increased epithelial cell detachment from the peripheral capillary wall and with increased remnant nephron albuminuria after reduction of nephron number in rats with established nephrosis. (J. Clin. Invest. 1990. 85:1119-1126.) adriamycin • epithelial cell $\bullet$ glomerulus $\bullet$ hypertrophy $\bullet$ nephrosis
\end{abstract}

\section{Introduction}

Reduction in functioning nephron number leads to increases in remnant glomerular filtration rate and remnant glomerular volume. It has recently been emphasized that these changes in remnant glomerular function and structure can cause glomerular injury after renal ablation in rats with initially normal kidneys and accelerate glomerular injury in rats with preexisting renal disease (1-4). A number of studies have related remnant glomerular injury to increased glomerular capillary pres-

This study was presented in part at the 21 st Annual Meeting of the American Society of Nephrology, San Antonio, TX, December 1988. Address reprint requests to Dr. Miller, Nephrology 111 R, Palo Alto Veterans Administration Medical Center, 3801 Miranda Avenue, Palo Alto, CA 94304.

Received for publication 10 April 1989 and in revised form 13 September 1989.

The Journal of Clinical Investigation, Inc.

Volume 85, April 1990, 1119-1126 sure after renal ablation (5). Further, recent studies suggest that glomerular hypertrophy promotes remnant glomerular injury by a mechanism which is independent of capillary hypertension $(4,6-8)$. The mechanisms by which glomerular hypertrophy promotes glomerular injury remain to be identified. In a previous study, we found that glomerular hypertrophy after reduction of nephron number in nephrotic rats was accompanied by a dramatic increase in remnant nephron proteinuria $(4,6)$. This finding suggests that glomerular hypertrophy can aggravate injury to glomerular epithelial cells. In the current study, morphometric techniques were used to identify changes in epithelial cell structure that accompany glomerular hypertrophy after renal ablation in rats with adriamycin nephrosis. Further studies sought to identify changes in epithelial cell structure in nephrotic rats subjected to dietary protein restriction, a maneuver which has been shown to reduce glomerular volume and proteinuria in these animals (9).

\section{Methods}

Male Munich Wistar rats weighing 235-275 g were given a single injection of adriamycin (doxarubicin $\mathrm{HCl}$ ), $3.3 \mathrm{mg} / \mathrm{kg}$, via tail vein under brevital anesthesia $(50 \mathrm{mg} / \mathrm{kg}$, i.p.). All rats were maintained on standard laboratory chow until $3 \mathrm{wk}$ after injection of adriamycin. They were then placed on a synthetic laboratory diet with protein content matched to the standard laboratory chow (24\% protein by weight, TD 85424, Teklad, Inc., Madison, WI). Baseline measurements were obtained at $4 \mathrm{wk}$ after injection of adriamycin and rats were divided into three groups with similar albumin excretion rate, serum albumin concentration, and body weight. A first group of nephrotic rats, group $1(n=8)$, served as controls and continued to receive the synthetic laboratory diet for $10 \mathrm{~d}$. A second group of rats, group $2(n=9)$, was subjected to $4 / 5$ ablation of renal mass by surgical right nephrectomy and ligation of two to three branches of the left renal artery and then maintained on the same $24 \%$ protein diet for 10 d. A third group of rats, group $3(n=8)$, received a synthetic diet with protein content reduced to $8 \%$ by weight (TD 87126 , Teklad, Inc.) for $10 \mathrm{~d}$. The mineral content of the two synthetic diets matched the mineral content of the standard laboratory chow. All animals had unrestricted access to food and drinking water. Repeat measurements of albumin excretion rate and serum albumin were made at $10 \mathrm{~d}$. After these measurements micropuncture studies were performed and kidneys were prepared for morphometric analysis.

\section{Micropuncture methods}

Rats were anesthetized with Inactin, $70 \mathrm{mg} / \mathrm{kg}$, i.p., and placed on a temperature regulated micropuncture table. A PE-50 tubing catheter was inserted in the left femoral artery and used for subsequent blood sampling and estimation of mean arterial pressure $(\overline{\mathrm{AP}}) .{ }^{1} \overline{\mathrm{AP}}$ was continuously monitored with an electronic transducer connected to a di-

1. Abbreviations used in this paper: $\overline{\mathrm{AP}}$, mean arterial pressure; HPEM, high-power electron micrograph; $K_{\mathrm{f}}$, ultrafiltration coefficient; $\mathrm{SN}$, single nephron; see footnotes to Tables I-IV for other abbreviations and symbols. 
rect writing recorder. After tracheostomy PE-50 catheters were inserted in the right and left internal jugular veins for infusion of rat plasma, saline, and radiolabeled inulin. Plasma was obtained from retired breeder rats made nephrotic by injection of adriamycin (3.5 $\mathrm{mg} / \mathrm{kg}$ ). Plasma was infused in an amount equal to $1 \%$ body weight for $40-45 \mathrm{~min}$, followed by a reduction of the infusion rate to $0.5 \mathrm{ml} / \mathrm{h}$ for the duration of the study. Saline was infused in an amount equal to $4 \%$ body weight for $80-100 \mathrm{~min}$, followed by a reduction of the infusion rate to $2.4 \mathrm{ml} / \mathrm{h}$ for the remainder of the study. After $100 \mathrm{~min}$, tritiated methoxy-inulin was added to the saline to achieve an infusion rate of $40-120 \mu \mathrm{Ci} / \mathrm{h}$ after a loading dose of $\sim 40 \mu \mathrm{Ci}$.

Micropuncture measurements were then carried out over two or three 30- to 40-min clearance periods. In each period, a 200- $\mu$ l arterial blood sample was obtained for determination of hematocrit and plasma inulin and protein concentrations. A renal vein blood sample was obtained with each arterial blood sample for determination of filtration fraction by renal vein inulin extraction. Time averaged hydraulic pressures were measured in surface glomerular capillaries (one to four determinations) ${ }^{2}$, proximal tubules (three to nine determinations), and efferent arterioles (two to five determinations) with a continuous recording servo-null micropipette transducer system (model V, Instrumentation for Physiology and Medicine, San Diego, CA). Hydraulic output from the servo system was coupled to a second channel of the direct writing recorder by means of a pressure transducer. Timed (3.5-4 min) samples of tubule fluid were collected from surface proximal convolutions of three to five nephrons for determination of single-nephron glomerular filtration rate (SNGFR).

\section{Morphometric methods}

After micropuncture study kidneys were fixed by retrograde aortic perfusion with $1.25 \%$ glutaraldehyde in $0.1 \mathrm{M}$ cacodylate buffer $(\mathrm{pH}$ 7.4). A 2-3-mm transverse section of kidney tissue was postfixed in $4 \%$ formaldehyde solution, methacrylate-embedded, and stained with hematoxylin-eosin for light microscopy and measurement of mean glomerular volume. Additional small blocks of outer cortical tissue were postfixed in osmium tetroxide, dehydrated in ethanol, and embedded in Epon. Thick sections were cut from these blocks and examined by light microscopy. When whole glomerular profiles were observed, thin sections were mounted on slotted grids and counterstained with uranyl acetate and lead citrate for electron microscopy. Electron micrographs were thus made from sections of outer cortical glomeruli selected without regard for severity of epithelial cell injury. The precise magnification of these electron micrographs was determined from micrographs of a calibration grid.

Mean glomerular volume. The mean glomerular tuft volume $\left(\bar{V}_{\mathrm{G}}\right)$ for each animal was determined from mean glomerular cross-sectional area $\left(\bar{A}_{\mathrm{G}}\right)$ as assessed by light microscopy. $\bar{A}_{\mathrm{G}}$ was determined on 100 consecutive glomerular profiles on each of two sections from each animal using a computer assisted morphometric unit (Bioquant Il software). $\bar{V}_{\mathrm{G}}$ was then calculated as:

$\bar{V}_{\mathrm{G}}=\beta / k \cdot\left(\bar{A}_{\mathrm{G}}\right)^{3 / 2}$,

where $\beta=1.38$ is the shape coefficient for spheres (the idealized shape of glomeruli) and $k=1.1$ is a size distribution coefficient $(10,11)$.

Surface area. Three surface areas were measured in the present study: $S_{\mathrm{PCW}}$, epithelial-peripheral capillary wall interface; $S_{\text {Mes }}$, epithelial-mesangial interface; $S_{\mathrm{PCWd}}$, peripheral capillary wall without overlying epithelium. These surface areas were assessed by determining the respective surface densities $S_{\mathrm{V}(\mathrm{PCW})}, S_{\mathrm{V}(\mathrm{Mes}) \text {, }}$ and $S_{\mathrm{V}(\mathrm{PCWd})}$ on low-magnification electron micrographs as described by Østerby and Gundersen (12). In each animal, three whole glomerular profiles were photographed at $\approx \times 750$ and printed on $11 \times 14$ paper to yield a final magnification of $\approx \times 1,750$. On each print a string polygon was drawn around the glomerulus and the print covered with a point and line

2. A single value for glomerular capillary pressure was obtained in only one rat. lattice in which each point was one end of a $20-\mathrm{mm}$ line segment. The number of points falling within the polygon and the intercepts of the line segments with the relevant surfaces was counted and the surface densities calculated as:

$S_{\mathrm{V}(\mathrm{PCW})}=\frac{2 \cdot \sum I_{(\mathrm{PCW})}}{k^{2} \cdot \sum P_{(\text {polygon })}}$

$S_{\mathrm{V}(\text { Mes })}=\frac{2 \cdot \sum I_{(\text {Mes })}}{k^{2} \cdot \sum P_{(\text {polygon })}}$

$S_{\mathrm{V}(\mathrm{PCWd})}=\frac{2 \cdot \sum I_{(\mathrm{PCWd})}}{k^{2} \cdot \sum P_{(\text {polygon })}}$,

where $\sum I_{(\mathrm{PCW})}=$ number of intercepts of epithelial-PCW interface with lines, $\Sigma I_{\text {(Mes) }}=$ number of intercepts of epithelial-Mes interface with lines, $\sum I_{(\mathrm{PCWd})}=$ number of intercepts of $\mathrm{PCW}$ without overlying epithelium with lines, $\sum P_{\text {(polygon) }}=$ number of points falling within the polygon, and $k=$ real length of the lattice line segments $=20 \mathrm{~mm}$ per print magnification. The average surface areas $S_{\mathrm{PCW}}, S_{\mathrm{Mes}}$, and $S_{\mathrm{PCWd}}$ expressed in square micrometers per glomerulus were then calculated as the products of the respective surface densities and the mean glomerular volume for each animal determined by light microscopy as described above.

Volumes of glomerular components. Volumes of glomerular components were measured on five high-power electron micrographs (HPEM) from each of four glomerular profiles per animal. These micrographs were printed on $8 \times 10$ paper at a final magnification of $\approx \times 13,000$ and covered with a $7 \times 9$ point grid. The fractional volumes of the following components were assessed: Epi, epithelial cells including podocytes; End, endothelial cells; Cap, capillary lumen; GBM, glomerular basement membrane; Mes, mesangium (cells and matrix). Fractional volumes for each component $(x)$ were calculated as:

$V_{\mathrm{V}(x)}=\frac{\sum P_{(x)}}{\sum P_{(\mathrm{Epi}+\mathrm{End}+\mathrm{Cap}+\mathrm{GBM}+\mathrm{Mes})}}$,

where $\sum P_{(x)}=$ number of points falling on component $(x)$, and where the denominator $\sum P_{(\mathrm{Epi}+\mathrm{End}+\mathrm{Cap}+\mathrm{GBM}+\mathrm{Mes})}$, is the number of points falling on the structures constituting the glomerular tuft, excluding the urinary space. The absolute volumes of individual components expressed as cubic micrometers per glomerulus were then calculated as:

$V_{(x)}=V_{\mathrm{V}(x)} \cdot \bar{V}_{\mathrm{G}} \cdot V_{\mathrm{V}_{\text {(tun) }}}$,

where $\bar{V}_{\mathrm{G}}$ is the mean glomerular volume determined by light microscopy, and where $V_{\left.\mathrm{v}_{\text {(tur }}\right)}$ is the fraction of this volume occupied by tuft as determined by point counting on the low power electron micrographs with

$V_{\mathrm{V}_{\text {(tuft) }}}=\frac{\sum P_{\text {(tuft) }}}{\sum P_{\text {(polygon) }}}$

where $\sum P_{\text {(tuf) }}=$ number of points within the string polygon falling on the tuft (excluding urinary space), and $\sum P_{(\text {polygon })}=$ total number of points falling within the polygon.

Slit frequency. Average slit frequency was determined by counting the number of slits overlying the peripheral capillary basement membrane on HPEM. Peripheral capillary basement membrane was distinguished from mesangial basement membrane by the loss of parallelism between epithelial and endothelial cells as described by Mauer et al. (13). Peripheral capillary basement membrane length was measured on HPEM using the computer assisted morphometric unit. Slit frequency was calculated as:

Slit Freq $=\frac{\sum \text { slits }}{\sum \text { BML }}$,

where $\Sigma$ slits $=$ the number of slits counted on the HPEM from four glomeruli from each animal, and $\Sigma$ BML = the total peripheral capillary basement membrane length on the HPEM for that animal. 


\section{Analytical}

Albumin excretion rate was determined by averaging two consecutive 24-h urine collections. Plasma protein concentration was measured by the modified Lowry technique to avoid interference by plasma lipids (14). Plasma and urine albumin concentrations were measured by rate nephelometry (Beckman Immunochemistry Analyzer II, Beckman Instruments, Inc., Palo Alto, CA), using anti-rat albumin antibody (Cooper Biomedical, Inc., Malvern, PA). Radioinulin content of plasma, urine, and tubule fluid was assessed by liquid-phase scintillation counting.

\section{Calculations and statistics}

Values for glomerular hemodynamic and morphometric parameters for each animal were recorded as the mean of values obtained in that animal. Group mean values were then calculated as the mean of values for individual animals. Efferent arteriolar plasma protein concentration $\left(C_{\mathrm{E}}\right)$ was calculated from the relation: $C_{\mathrm{E}}=C_{\mathrm{A}} /(1-\mathrm{FF})$. A recently derived set of equations relating oncotic pressure to plasma protein concentration in nephrotic rats was used to calculate plasma oncotic pressure (15). A standard mathematical model was used to derive the glomerular capillary ultrafiltration coefficient $\left(K_{\mathrm{f}}\right)$ from these values for oncotic pressure and from measured parameters (16). The statistical significance of differences among values for individual parameters in the three experimental groups was evaluated by the analysis of variance. Values for $\mathrm{SN}_{\text {alb }}$ were log-transformed for statistical analysis. The Newman-Keuls multiple range test was used to assess the significance of differences between individual group means (three comparisons) with significance defined as $P<0.05$. Comparison of values for blood pressure and albumin excretion rate at different time points within each group was made by the paired $t$ test. Results are expressed as means $\pm \mathrm{SE}$ throughout.

\section{Results}

Albumin excretion rate and body growth. By design, baseline albumin excretion rate at $4 \mathrm{wk}$ after injection of adriamycin was similar in the three groups (Table I), averaging $838 \pm 51$ $\mathrm{mg} / \mathrm{d}$ in group $1,820 \pm 69 \mathrm{mg} / \mathrm{d}$ in group 2 , and $874 \pm 56 \mathrm{mg} / \mathrm{d}$ in group 3. Albumin excretion rate rose slightly to $923 \pm 63$ $\mathrm{mg} / \mathrm{d}$ in group 1 animals at $10 \mathrm{~d}$. Despite four-fifths reduction in nephron mass, albumin excretion rate was reduced only slightly to $646 \pm 27 \mathrm{mg} / \mathrm{d}$ in group 2 rats at $10 \mathrm{~d}$. Dietary protein restriction reduced albumin excretion rate to $578 \pm 27$ $\mathrm{mg} / \mathrm{d}$ in group 3 rats at $10 \mathrm{~d}$. Baseline values for serum albu-

Table I. Body Weight and Albuminuria

\begin{tabular}{|c|c|c|c|c|c|}
\hline & & BW & $\mathrm{U}_{\mathrm{alb}} \mathrm{V}$ & $\mathrm{S}_{\mathrm{alb}}$ & $\mathrm{C}_{\mathrm{alb}}$ \\
\hline & & $g$ & $m g / d$ & $g / d l$ & $\mathrm{ml} / \mathrm{min}$ \\
\hline \multirow{2}{*}{$\begin{array}{l}\text { Group 1 } \\
\quad(n=8)\end{array}$} & Od & $289 \pm 6$ & $838 \pm 51$ & $1.06 \pm 0.12$ & $0.060 \pm 0.008$ \\
\hline & $10 \mathrm{~d}$ & $292 \pm 7$ & $923 \pm 63$ & $0.94 \pm 0.14$ & $0.077 \pm 0.009^{\ddagger}$ \\
\hline \multirow{2}{*}{$\begin{array}{c}\text { Group 2 } \\
\quad(n=9)\end{array}$} & od & $291 \pm 7$ & $820 \pm 69$ & $0.99 \pm 0.10$ & $0.063 \pm 0.009$ \\
\hline & $10 d$ & $264 \pm 5^{*}$ & $646 \pm 27^{* \pm}$ & $1.11 \pm 0.09$ & $0.043 \pm 0.004^{* \ddagger}$ \\
\hline \multirow{2}{*}{$\begin{array}{c}\text { Group } 3 \\
\quad(n=8)\end{array}$} & Od & $280 \pm 5$ & $874 \pm 56$ & $1.05 \pm 0.12$ & $0.066 \pm 0.010$ \\
\hline & $10 \mathrm{~d}$ & $264 \pm 4^{*}$ & $578 \pm 27^{* \ddagger}$ & $1.15 \pm 0.09$ & $0.037 \pm 0.003^{* \ddagger}$ \\
\hline
\end{tabular}

Values are mean \pm SEM.

Abbreviations: $\mathrm{BW}$, body weight; $\mathrm{U}_{\mathrm{alb}} \mathrm{V}$, albuminuria; $\mathrm{S}_{\text {alb }}$, serum albumin concentration; $\mathrm{C}_{\mathrm{alb}}$, albumin clearance; $0 \mathrm{~d}$, baseline value at $4 \mathrm{wk}$ after administration of adriamycin; $10 \mathrm{~d}$, final value at $10 \mathrm{~d}$ after baseline value.

* $P<0.05$ group 2 and 3 vs. group 1 .

$\ddagger P<0.0510 \mathrm{~d}$ value vs. $0 \mathrm{~d}$ value. min concentration were similar in the three groups and were not altered significantly at ten days. Baseline values for body weight were also similar in the three groups. Body weight was slightly but significantly reduced in group 2 and group 3 rats at $10 \mathrm{~d}$, falling from $291 \pm 7 \mathrm{~g}$ to $264 \pm 5 \mathrm{~g}$ in group 2 rats and from $280 \pm 5 \mathrm{~g}$ to $264 \pm 4 \mathrm{~g}$ in group 3 animals.

Glomerular hemodynamic function. Mean values for $\overline{\mathrm{AP}}$ under anesthesia, hematocrit, GFR, SNGFR, and the pressures and flows governing glomerular ultrafiltration for the three groups of rats are summarized in Table II. $\overline{\mathrm{AP}}$ was increased after renal ablation in nephrotic rats, averaging $150 \pm 6$ $\mathrm{mm} \mathrm{Hg}$ in group 2 as compared with $118 \pm 2 \mathrm{~mm} \mathrm{Hg}$ in group 1 and $116 \pm 3 \mathrm{~mm} \mathrm{Hg}$ in group 3. Hematocrit and plasma protein concentration was not different in the three groups.

As expected, ablation of a major portion of the renal mass led to a decline in total GFR in group 2. GFR was reduced to $0.56 \pm 0.05 \mathrm{ml} / \mathrm{min}$ in group 2 as compared to $1.68 \pm 0.12 \mathrm{ml} /$ min in group 1. As it does in normal rats, reduction in renal mass evoked remnant nephron hyperfiltration, with SNGFR increasing to $56 \pm 3 \mathrm{nl} / \mathrm{min}$ in group 2 as compared to $36 \pm 2$ $\mathrm{nl} / \mathrm{min}$ in group 1 . In accord with our previous results, however, the hemodynamic changes responsible for the increase in remnant nephron GFR in nephrotic rats were different than those identified in normal rats $(2,6)$. Thus the increase in remnant SNGFR in group 2 rats was largely due to increases in glomerular plasma flow rate $\left(\mathrm{Q}_{\mathrm{A}}\right)$ and $K_{\mathrm{f}}$ while no significant increase in $\Delta \mathrm{P}$ over the value observed in group 1 rats was observed. Dietary protein restriction did not significantly alter glomerular hemodynamic function in group 3. Values for total GFR, $S N G F R, Q_{A}$, and $\Delta P$ in group 3 were slightly reduced as compared to the values observed in group 1 , but the differences were not statistically significant.

The ratio of total GFR to SNGFR was used to estimate the functioning nephron number in each animal. Mean values of $47 \pm 3 \times 10^{3}$ and $48 \pm 4 \times 10^{3}$, respectively, were obtained in group 1 and group 3 rats with intact kidneys. Renal ablation reduced estimated nephron number in group 2 rats to $10 \pm 1$ $\times 10^{3}$. Estimates of nephron number in each animal were in turn used to calculate values for single nephron albumin excretion rate as summarized in Table III. A mean value of $20 \pm 2$ $\mu \mathrm{g} / \mathrm{d}$ was obtained in group 1 . The calculated value for single nephron albumin excretion rate was increased threefold to $68 \pm 7 \mu \mathrm{g} / \mathrm{d}$ after renal ablation in group 2 and was reduced to $12 \pm 1 \mu \mathrm{g} / \mathrm{d}$ by dietary protein restriction in group 3 .

Glomerular structure. Mean values for glomerular volume and for the surface areas and volumes of different glomerular components are summarized in Table IV. Glomerular volume in group 1 nephrotic rats averaged $1.44 \pm 0.04 \times 10^{6} \mu \mathrm{m}^{3}$, a value no different than that obtained in normal male MunichWistar rats with similar body weight in our laboratory. Increased remnant nephron albuminuria at $10 \mathrm{~d}$ after renal ablation was associated with hypertrophy of remnant glomeruli in group 2. At this stage of glomerular hypertrophy, no increase in the surface area of the peripheral capillary wall, $S_{\mathrm{PCW}}$, or the epithelial-mesangial interface, $S_{\text {MES }}$, was apparent. There was, however, a marked increase in the area of epithelial cell detachment from the basement membrane of the peripheral capillary wall, $\mathbf{S}_{\mathbf{P C W d}}$. Epithelial cell detachment from the peripheral capillary wall, as illustrated in Fig. 1, has regularly been observed in rats with toxic epithelial cell injury induced by puromycin aminonucleoside and by adriamycin $(17,18)$. Application of quantitative morphometric techniques revealed 


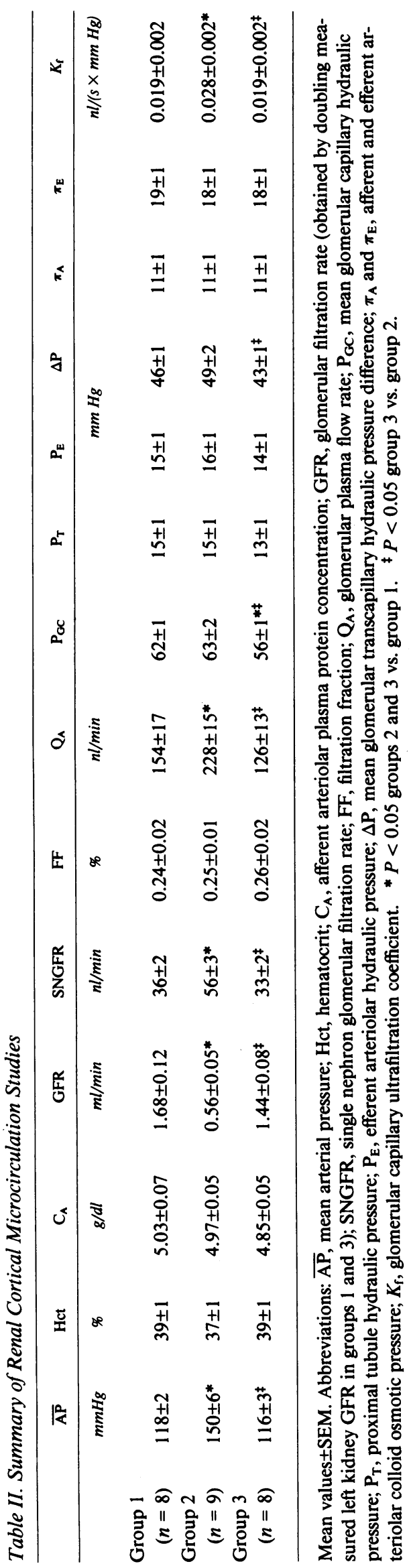

Table III. Estimated Single Nephron Albuminuria at $10 \mathrm{~d}$

\begin{tabular}{lccc}
\hline & Group 1 & Group 2 & Group 3 \\
\hline $\mathrm{U}_{\text {alb }} \mathrm{V}(m g / d)$ & $923 \pm 63$ & $646 \pm 27^{*}$ & $578 \pm 27^{*}$ \\
$\mathrm{Nephron}^{*}\left(n, \times 10^{3}\right)$ & $47 \pm 3$ & $10 \pm 1^{*}$ & $48 \pm 4^{\ddagger}$ \\
$\mathrm{SN}_{\text {alb }}(\mu g / d)$ & $20 \pm 2$ & $68 \pm 7^{*}$ & $12 \pm 1^{* \pm}$
\end{tabular}

Values are mean $\pm \mathrm{SE}$.

Abbreviations: $\mathrm{U}_{\mathrm{alb}} \mathrm{V}$, albuminuria at $10 \mathrm{~d} ; \mathrm{SN}_{\mathrm{alb}}$, single nephron albumin excretion rate calculated from $\mathrm{U}_{\mathrm{alb}} \mathrm{V}$ and nephron number.

${ }^{*} P<0.05$ groups 2 and 3 vs. group 1 .

${ }^{\ddagger} P<0.05$ group 3 vs. group 2 .

that the area of epithelial cell detachment from the peripheral capillary wall was $0.016 \pm 0.005 \times 10^{5} \mu \mathrm{m}^{2}$, in group 1 nephrotic rats in the present study. The area of epithelial cell detachment increased to $0.065 \pm 0.017 \times 10^{5} \mu \mathrm{m}^{2}$ in association with glomerular hypertrophy in group 2 . This change represents an increase in the area of epithelial detachment from $1.0 \pm 0.3 \%$ to $4.3 \pm 1.2 \%$ of the total peripheral capillary wall, as illustrated in Fig. 2.

Glomerular hypertrophy was associated with significant increases in epithelial cell volume, endothelial cell volume, and glomerular basement membrane volume in group 2 rats. Epithelial slit frequency was determined to assess whether the extent of epithelial foot process retraction was altered in the course of glomerular and epithelial cell hypertrophy in nephrotic rats. As expected, slit frequency in group 1 nephrotic rats, $0.42 \pm 0.04$ slits $/ \mu \mathrm{m}$, was reduced below the value obtained in normal rats of similar body weight in our laboratory, as illustrated in Fig. 2. No further reduction in slit frequency was associated with the threefold increase in remnant nephron albuminuria which accompanied glomerular hypertrophy after renal ablation in group 2 rats.

In contrast to the increase in remnant nephron albuminuria associated with glomerular hypertrophy after renal ablation in group 2, reduction in albuminuria was associated with reduction of glomerular volume after dietary protein restriction in group 3. The magnitude of the reduction in albuminuria in group 3, however, was less than the magnitude of the increase in remnant nephron albuminuria in group 2. Reduction in glomerular volume in group 3 was not accompanied by a perceptible change in the area of epithelial cell detachment from the basement membrane or in epithelial cell slit frequency, as illustrated in Fig. 2.

\section{Discussion}

Recent studies have emphasized that progressive glomerular injury follows reduction of nephron number in the rat. Numerous studies have documented early development of glomerular injury following ablation of renal mass in rats with initially normal kidneys $(1,2)$. Further studies have shown that ablation of renal mass accelerates the progression of experimental renal disease $(3,4)$.

The potential analogy of renal disease progression in rats subjected to renal ablation and humans with renal insufficiency has prompted investigation of the mechanisms responsible for glomerular injury following reduction in nephron number. A variety of mechanisms of injury have been identi- 
fied (19). One line of evidence suggests that changes in glomerular function and structure which serve to elevate remnant nephron glomerular filtration rate cause remnant glomerular injury (20). Thus elevated capillary pressure has been shown to accelerate remnant glomerular injury in several disease models $(5,21)$. Recent studies suggest that glomerular hypertrophy also promotes glomerular injury independent of glomerular capillary hypertension (4, 6-8). In rats with established nephrosis, glomerular hypertrophy following renal ablation is accompanied by a large increase in remnant nephron proteinuria $(4,6)$. This increase in remnant nephron proteinuria is followed by rapid development of glomerular sclerosis (4). The main objective of the present study was to identify a structural basis for increased remnant nephron proteinuria associated with glomerular hypertrophy in nephrotic rats.

Our results show that glomerular hypertrophy in nephrotic rats is associated with increased epithelial cell detachment from the peripheral capillary basement membrane. Glomerular hypertrophy at $10 \mathrm{~d}$ after renal ablation in group 2 rats was accompanied by a fourfold increase in the mean area of epithelial detachment from the peripheral capillary basement membrane. This structural change was associated with a threefold increase in remnant nephron albuminuria. Epithelial cell detachment from the basement membrane has previously been associated with proteinuria in rats with adriamycin and puromycin nephrosis and in rats with initially normal kidneys subjected to renal ablation $(17,18,22)$. Epithelial cell detachment from the basement membrane has also been observed in several human glomerular diseases characterized by heavy proteinuria $(23,24)$. In rats with puromycin nephrosis the onset of proteinuria coincides with the appearance of epithelial detachment from the basement membrane and the degree of proteinuria is correlated with the extent of this lesion $(18,24,25)$. These observations have prompted the suggestion that increased protein passage through capillary wall areas denuded of epithelial cells causes proteinuria after toxic epithelial cell injury. The present results are consistent with this hypothesis, and show further that epithelial cell detachment from the peripheral capillary wall increases when injured glomeruli undergo compensatory glomerular hypertrophy.

The extent of epithelial cell injury was assessed not only by measuring epithelial cell denudation from the basement membrane but also by estimating the degree of broadening of epithelial cell foot processes as reflected by epithelial slit frequency. Broadening or "fusion" of epithelial cell foot processes is regularly associated with heavy proteinuria in experimental and in human renal disease. Studies employing scanning electron microscopy have established that this alteration in epithelial cell structure does not reflect actual fusion of adjacent foot processes but rather retraction of foot processes and simplification of epithelial cell structure (26). As expected, group 1 nephrotic rats in the current study exhibited broadening of epithelial cell foot processes reflected by reduction in epithelial slit frequency below values observed in normal rats. Of note, however, no further broadening of epithelial cell foot processes accompanied the threefold increase in remnant nephron albuminuria associated with nephron loss and compensatory glomerular hypertrophy in group 2 rats. The average slit frequency of $0.52 \pm 0.05$ slits $/ \mu \mathrm{m}$ observed in group 2 was not different than the average slit frequency of $0.42 \pm 0.04$ slits $/ \mu \mathrm{m}$ observed in group 1 . This finding is consistent with the recent demonstration by Fries et al. (27) that protein ex-

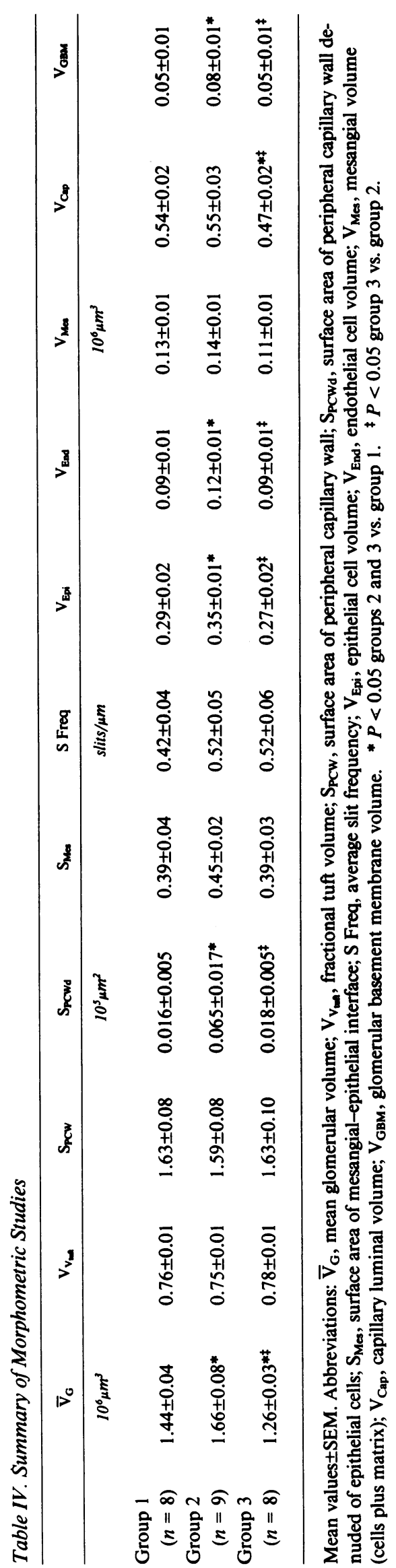

Glomerular Hypertrophy and Epithelial Cell Injury 


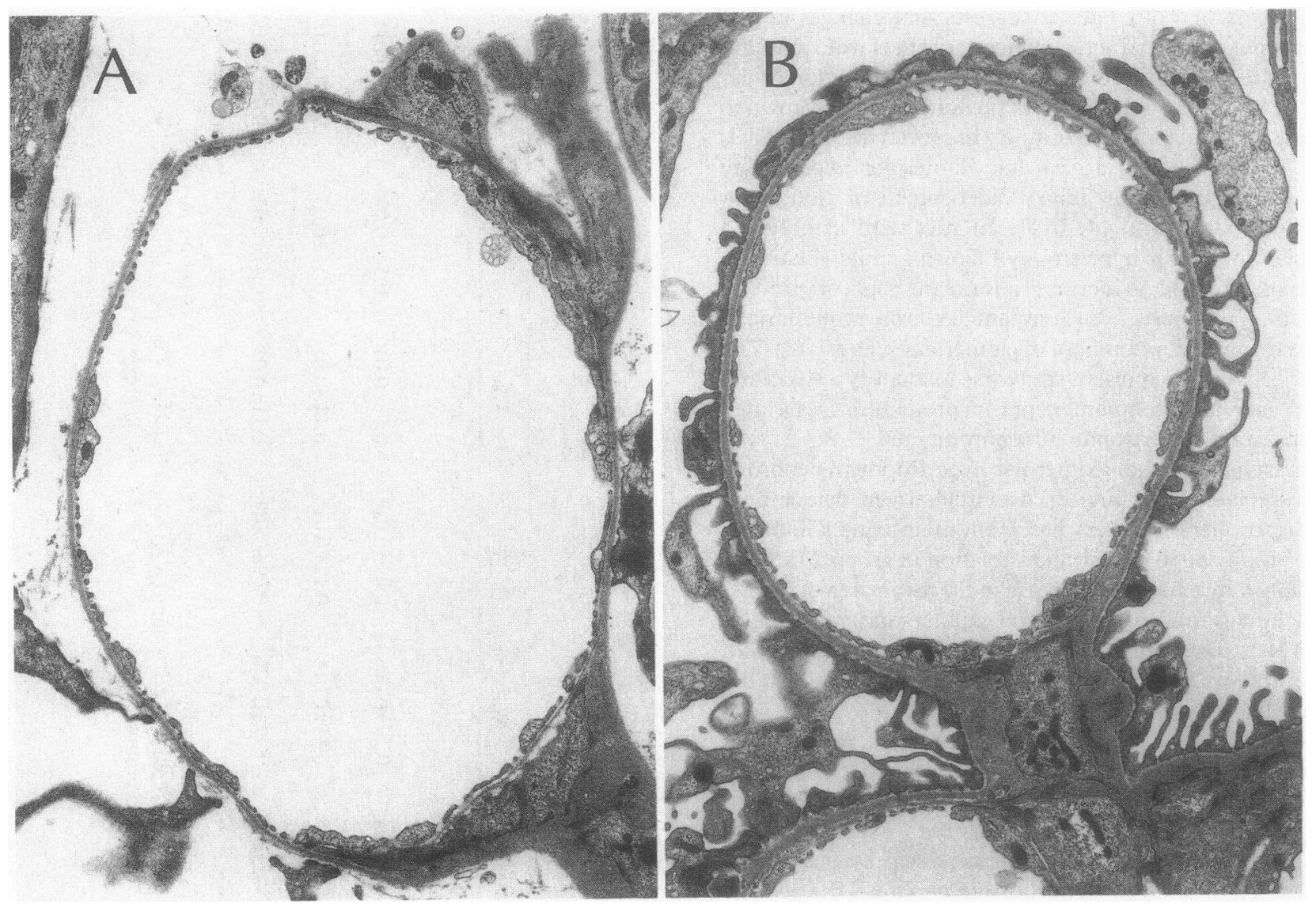

Figure 1. Epithelial cell injury after adriamycin nephrosis and renal ablation. $(A)$ A capillary loop showing extensive detachment of epithelial cell foot processes. The severe injury illustrated in this micrograph was seen only focally. $(B)$ Another capillary loop from the same section of the same glomerulus showing relative preservation of epithelial cell structure. $\times 7,500$.

cretion rate is not correlated with epithelial cell foot process width in nephrotic humans. Together, our results and those of Fries et al. (27) indicate that impairment of glomerular permselectivity is not determined by the extent of foot process retraction. By themselves, these results do not exclude the possibility that foot process retraction represents a threshold response, occurring when a certain degree of proteinuria is exceeded. Previous studies have demonstrated, however, that retraction of epithelial cell foot processes precedes development of proteinuria in rats with puromycin nephrosis $(18,24)$. Results of these studies seem inconsistent with the hypothesis that foot process retraction is a consequence of impaired permselectivity and proteinuria.

Micropuncture studies were performed to assess the dependence of remnant nephron albuminuria and remnant glomerular structure on glomerular capillary pressure. These studies showed that increased remnant nephron albuminuria and epithelial cell detachment from the basement membrane were not caused by an increase in $\Delta \mathrm{P}$ after renal ablation in nephrotic rats. The mean $\Delta \mathrm{P}$ value of $49 \pm 2 \mathrm{~mm} \mathrm{Hg}$ in group 2 was not significantly increased above the mean $\Delta P$ value of $46 \pm 1 \mathrm{~mm} \mathrm{Hg}$ in group 1 . This result is consistent with our previous finding that remnant nephron proteinuria increases after renal ablation in nephrotic rats even when a converting enzyme inhibitor is used to prevent any increase in $\Delta P(6)$. Together, these results suggest that changes in epithelial cell structure observed in group 2 rats can properly be attributed to glomerular hypertrophy rather than to glomerular capillary hypertension.

A further objective of the present study was to identify glomerular structural changes responsible for decreased albuminuria after restriction of protein intake. Recent studies have shown that restriction of protein intake reduces proteinuria both in nephrotic rats and in nephrotic humans (28-31). The current study showed that reduction of albuminuria was associated with reduction of glomerular volume after dietary protein restriction in rats with established adriamycin nephrosis. Beukers et al. (9) have previously found that development of proteinuria and glomerular volume are reduced when dietary protein restriction is initiated at the time of adriamycin injection. The present study did not, however, identify any changes in epithelial cell structure associated with reduction of albuminuria and reduction of glomerular volume in protein restricted nephrotic rats. In particular, no decrease in the area of epithelial cell detachment from the peripheral capillary basement membrane was observed in protein-restricted nephrotic rats. The mean area of detachment of $0.018 \pm 0.005 \times 10^{5} \mu \mathrm{m}^{2}$ per glomerulus in group 3 was no different from the mean area of detachment of $0.016 \pm 0.005 \times 10^{5} \mu \mathrm{m}^{2}$ per glomerulus in group 1 . The precision of these results, however, is not sufficient to establish that protein restriction did not affect epithelial cell detachment from the basement membrane. Marked intraglomerular variability of epithelial cell injury was observed in the current study as in previous studies of toxic epi- 

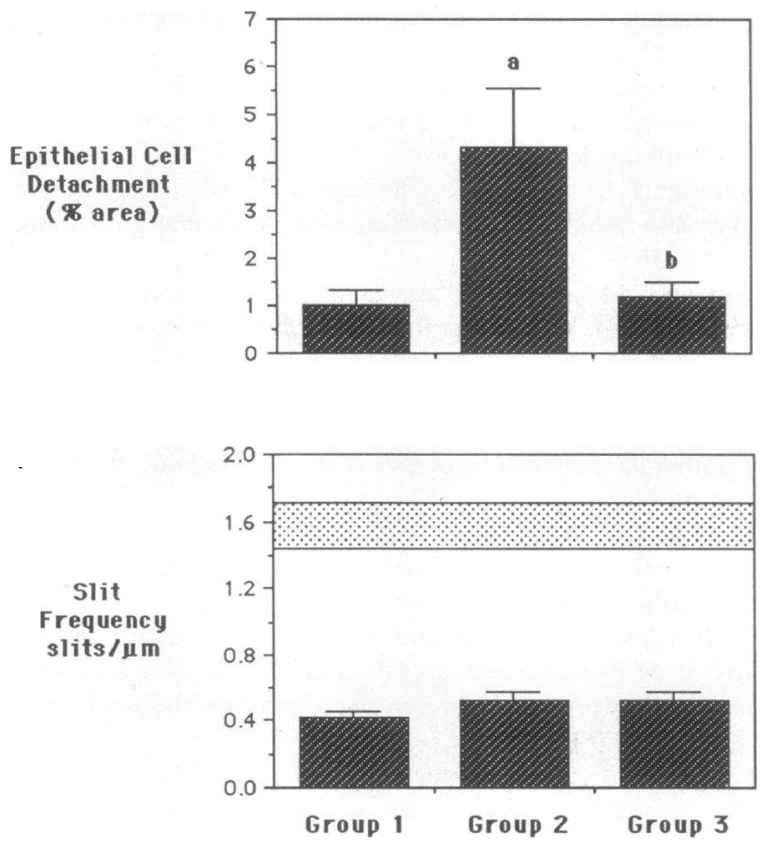

Figure 2. Area of epithelial cell denudation from the peripheral capillary wall (expressed as percent peripheral capillary wall area) and average slit frequency in nephrotic rats. Epithelial cell denudation from the peripheral capillary wall increased in group 2 rats subjected to renal ablation. Foot process retraction in each group was reflected by reduction in average slit frequency below normal values. Average slit frequency was not altered following renal ablation in group 2 or protein restriction in group $3 .{ }^{a} P<0.05$ group 2 vs. group $1 .{ }^{b} P$ $<0.05$ group 3 vs. group 2 . The shaded band depicts the normal range (mean $\pm 2 \mathrm{SD}$ ) for slit frequency in male Munich-Wistar rats (from reference 34 ).

thelial cell injury induced by puromycin (18). Because of this variability, examination of a large number of glomerular profiles would be required to determine whether the area of epithelial cell detachment changed in proportion to albumin excretion rate in group 3 rats. Surface area measurements obtained from 24 glomerular profiles in groups 1 and 3 in the current study cannot distinguish whether dietary protein restriction reduces epithelial cell detachment from the basement membrane or whether this dietary treatment reduces albuminuria in nephrotic rats by a different mechanism. The present study does suggest, however, that reduction in albuminuria cannot be attributed to reduction in $\Delta \mathrm{P}$ in protein restricted rats with adriamycin nephrosis. $\Delta \mathrm{P}$ was only slightly lower in group 3 than in group 1 in the current study, and this difference did not achieve statistical significance. We have previously shown that albuminuria in rats with adriamycin nephrosis is not reduced by converting enzyme inhibitor treatment which causes a larger, statistically significant reduction in $\Delta \mathrm{P}(32)$. Similarly, Beukers et al. (9) have shown that proteinuria in rats with adriamycin nephrosis is not reduced by converting enzyme inhibitor treatment which causes a prominent reduction in systemic blood pressure. Together, these results indicate that lowering of $\Delta \mathbf{P}$ cannot by itself account for the reduction in albuminuria in nephrotic rats maintained on a low protein diet. It remains possible, however, that reduction in $\Delta \mathrm{P}$ acts in concert with reduction in glomerular volume to reduce the albumin excretion rate in these animals.
Previous studies have shown that normal rats subjected to renal ablation exhibit a gradual increase in proteinuria. Development of proteinuria in these animals can be largely prevented by normalization of glomerular capillary pressure ( 2 , 33). These findings suggest that normal epithelial cells can maintain their structure and preserve glomerular permselective function as the glomerulus enlarges following reduction in nephron number. In contrast, a large increase in remnant nephron albuminuria was observed at ten days following renal ablation in nephrotic rats in the present study. This increase in remnant nephron albuminuria was associated with increased epithelial cell detachment from the peripheral capillary wall. These findings suggest that injured epithelial cells are unable to maintain their attachment to the capillary wall when the glomerulus enlarges in nephrotic animals. In a previous study, we found that increased remnant nephron albuminuria was associated with rapid development of glomerular sclerosis in nephrotic rats with reduced nephron number (4). This finding and the results of the current study lead us to speculate that glomerular hypertrophy can accelerate glomerular sclerosis by aggravating epithelial cell injury when nephron number is reduced in the setting of established nephrosis.

\section{Acknowledgments}

We are grateful to Brittmarie Anderssen and to Helen Kwan for expert technical assistance.

This study was supported by grants from the Research Service of the Veterans Administration and the National Institutes of Health (DK-35931 and DK-35734). Dr. Miller receives support as an Associate Investigator of the Veterans Administration. Dr. Scholey is supported by a research fellowship from the Medical Research Council of Canada.

\section{References}

1. Purkerson, M. L., P. E. Hoffsten, and S. Klahr. 1976. Pathogenesis of the glomerulopathy associated with renal infarction in rats. Kidney Int. 9:407-417.

2. Anderson, S., T. W. Meyer, H. G. Rennke, and B. M. Brenner. 1985. Control of glomerular hypertension limits glomerular injury in rats with reduced renal mass. J. Clin. Invest. 76:612-619.

3. Brenner, B. M., T. W. Meyer, and T. H. Hostetter. 1982. Dietary protein intake and the progressive nature of kidney disease. $N$. Engl. J. Med. 307:652-659.

4. Fries, J. W. U., Sandstrom, D. J., T. W. Meyer, and H. G. Rennke. 1989. Glomerular hypertrophy and epithelial cell injury modulate progressive glomerulosclerosis in the rat. Lab. Invest. 60:205217.

5. Brenner, B. M. 1985 . Nephron adaptation to renal injury or ablation. Am. J. Physiol. 249:F324-F337.

6. Meyer, T. W., and H. G. Rennke. 1988. Increased singlenephron protein excretion after renal ablation in nephrotic rats. Am. J. Physiol. 255:F1243-F1248.

7. Yoshida, Y., A. Fogo, and I. Ichikawa. 1989. Glomerular hemodynamic changes vs. hypertrophy in experimental glomerular sclerosis. Kidney Int. 35:654-660.

8. Daniels, B. S., and T. H. Hostetter. 1986. Dietary salt and glomerular damage: the role of renal growth. Clin. Res. 34:593A. (Abstr.)

9. Beukers, J. J. B., P. J. Hoedemaeker, and J. J. Weening. 1988. A comparison of the effects of converting-enzyme inhibition and protein restriction in experimental nephrosis. Lab. Invest. 59:631-639.

10. Weibel, E. R. 1979. Stereological Methods: Practical Methods for Biological Morphometry. Volume 1. Academic Press, Ltd., London. 51-57.

11. Hirose, Kr., R. Østerby, M. Nozawa, and H. J. G. Gundersen. 
1982. Development of glomerular lesions in experimental long-term diabetes in the rat. Kidney Int. 21:689-695.

12. Østerby, R., and H. J. G. Gunderson. 1980. Fast accumulation of basement membrane material and the rate of morphologic changes in acute experimental diabetic glomerular hypertrophy. Diabetologia. 18:493-500.

13. Mauer, S. M., M. W. Steffes, E. N. Ellis, D. E. R. Sutherland, D. M. Brown, and F. C. Goetz. 1984. Structural-functional relationships in diabetic nephropathy. J. Clin. Invest. 74:1143-1155.

14. Markwell, M. A. K., S. M. Haas, L. L. Bieber, and N. E. Tolbert. 1978. A modification of the Lowry procedure to simplify protein determination in membrane and lipoprotein samples. Anal. Biochem. 87:206-210.

15. Miller, P. L., and T. W. Meyer. 1988. Plasma protein concentration and colloid osmotic pressure in nephrotic rats. Kidney Int. 34:220-223.

16. Deen, W. M., J. L. Troy, R. Robertson, and B. M. Brenner. 1973. Dynamics of glomerular ultrafiltration in the rat. IV. Determination of the ultrafiltration coefficient. J. Clin. Invest. 52:1500-1508.

17. Weening, J. J., and H. G. Rennke. 1983. Glomerular permeability and polyanion in adriamycin nephrosis in the rat. Kidney Int. 24:152-159.

18. Ryan, G. B., and M. J. Karnovsky. 1975. An ultrastructural study of the mechanisms of proteinuria in aminonucleoside nephrosis. Kidney Int. 8:219-232.

19. Olson, J. L., and R. H. Heptinstall. 1988. Nonimmunologic mechanisms of glomerular injury. Lab. Invest. 59:564-578.

20. Rennke, H. G. 1986. Structural alterations associated with glomerular hyperfiltration. In The Progressive Nature of Renal Disease. W. E. Mitch, B. M. Brenner, and J. H. Stein, editors. Churchill Livingstone, New York. 111.

21. Baldwin, D. S., and J. Neugarten. 1987. Role of hypertension in the evolution of renal diseases. Contrib. Nephrol. 54:63-76.

22. Olson, J. L., T. H. Hostetter, H. G. Rennke, B. M. Brenner, and M. A. Venkatachalam. 1982. Altered glomerular permselectivity and progressive sclerosis following extreme ablation of renal mass. Kidney Int. 22:112-126.

23. Grishman, E., and J. Churg. 1975. Focal glomerular sclerosis in nephrotic patients: an electron microscopic study of glomerular podocytes. Kidney Int. 7:111-122.

24. Messina, A., D. J. Davies, P. C. Dillane, and G. B. Ryan. 1987. Glomerular epithelial abnormalities associated with the onset of proteinuria in aminonucleoside nephrosis. Am. J. Pathol. 126:220-229.

25. Kanwar, Y. S., and L. J. Rosenzweig. 1982. Altered glomerular permeability as a result of focal detachment of the visceral epithelium. Kidney Int. 21:565-574.

26. Arakawa, M., and J. Tokunaga. 1972. A scanning electron microscopic study of the glomerulus: further considerations of the mechanism of the fusion of podocyte terminal processes in nephrotic rats. Lab. Invest. 27:366-371.

27. Fries, J. W. U., H.-J. Rumpelt, and W. Thoenes. 1987. Alterations of glomerular podocytic processes in immunologically mediated glomerular disorders. Kidney Int. 32:742-748.

28. Neugarten, J., H. D. Feiner, R. G. Schacht, and D. S. Baldwin. 1983. Amelioration of experimental glomerulonephritis by dietary protein restriction. Kidney Int. 24:595-601.

29. Nath, K. A., S. M. Kren, and T. H. Hostetter. 1986. Dietary protein restriction in established renal injury in the rat: selective role of glomerular capillary pressure in progressive glomerular dysfunction. $J$. Clin. Invest. 78:1199-1205.

30. Kaysen, G. A., J. Gambertoglio, J. Felts, and F. N. Hutchison. 1987. Albumin synthesis, albuminuria and hyperlipemia in nephrotic patients. Kidney Int. 31:1368-1376.

31. Rosenberg, M. E., J. E. Swanson, B. L. Thomas, and T. H. Hostetter. 1987. Glomerular and hormonal responses to dietary protein intake in human renal disease. Am. J. Physiol. 253:F1083-F1090.

32. Scholey, J. W., P. L. Miller, H. G. Rennke, and T. W. Meyer. 1989. Effect of converting enzyme inhibition on the course of adriamycin induced nephropathy. Kidney Int. 36:816-822.

33. Anderson, S., H. G. Rennke, and B. M. Brenner. 1986. Therapeutic advantage of converting enzyme inhibitors in arresting progressive renal disease associated with systemic hypertension in the rat. $J$. Clin. Invest. 77:1993-2000.

34. Scholey, J. W., P. L. Miller, H. G. Rennke, and T. W. Meyer. 1989. Converting enzyme inhibitor treatment reverses broadening of epithelial cell foot processes in rats with reduced nephron number. Kidney Int. 35:437. (Abstr.) 